\title{
GENERAL ISSUES
}

УДК 619:616-099-02:615.9

\section{ГЕПАТОПРОТЕКТОРНАЯ \\ ЭФФЕКТИВ НОСТЬ ПРЕПАРАТА НА ОСНоВЕ ЛЕЦИТИНА \\ ПРИ ТОКСИЧЕСКОМ ПОРАЖЕНИИ ПЕЧЕНИ ЖИВОТНЫХ В УСЛОВИЯХ ЭКСПЕРИМЕНТА}

\author{
Е. В. Кузьминова' ${ }^{1}$ М. П. Семененко ${ }^{2}$, Е. В. Тяпкина ${ }^{3}$, В. А. Соболев ${ }^{4}$ \\ ${ }^{1}$ Ведущий научный сотрудник, доктор ветеринарных наук, Краснодарский НИВИ, г. Краснодар, e-mail: niva1430@mail.ru \\ 2 Заведующий отделом, доктор ветеринарных наук, Краснодарский НИВИ, г. Краснодар \\ ${ }^{3}$ Старший научный сотрудник, кандидат ветеринарных наук, Краснодарский НИВИ, г. Краснодар \\ ${ }^{4}$ Аспирант, Краснодарский НИВИ, г. Краснодар
}

\section{PEЗЮME}

Представлены данные по оценке эффективности лецитинового препарата при экспериментальном токсическом поражении печени лабораторных животных. Эксперименты проведены на крысах, содержащихся в одинаковых условиях, прошедших карантинный режим вивария и не имеющих внешних признаков заболеваний. Группы животных формировались по принципу парных аналогов. Острое токсическое поражение печени моделировали однократным введением четыреххлористого углерода (0,3 мг/кг массы тела). Установлено, что на второй день после введения крысам четыреххлористого углерода зарегистрированы внешние признаки интоксикации: отказ от корма, угнетение, одышка, повышение температуры тела. Применение per os рапсового лецитина за час до введения гепатотоксиканта и далее ежедневно в последующие 30 дней в дозе 1 мл/кг массы тела снижает клинические проявления интоксикации и повышает сохранность крыс. Фармакологический эффект лецитина проявляется улучшением биохимических параметров и функционального состояния печени лабораторных животных на фоне экспериментального острого гепатита. Полученные данные могут послужить основанием для применения рапсовых лецитинов в качестве гепатопротекторов природного происхождения с возможностью их использования как биологически активных добавок или действующих начал лекарственных средств, предназначенных для лечения заболеваний печени у животных.

\section{HEPATOPROTECTIVE EFFECT \\ OF LECITHIN-BASED PREPARATION ON EXPERIMENTAL ANIMAL LIVER TOXICITY}

\section{Ye. V. Kuzminova', M. P. Semenenko², Ye. V. Tyapkina ${ }^{3}$, V. A. Sobolev ${ }^{4}$}

${ }^{1}$ Leading Researcher, Doctor of Science (Veterinary Medicine), Krasnodar Scientific-Research Veterinary Institute, Krasnodar, e-mail:niva1430@mail.ru ${ }^{2}$ Head of the Department, Doctor of Science (Veterinary Medicine), Krasnodar Scientific-Research Veterinary Institute, Krasnodar ${ }^{3}$ Senior Researcher, Candidate of Science (Veterinary Medicine), Krasnodar Scientific-Research Veterinary Institute, Krasnodar

${ }^{4}$ Post-Graduate Student, Krasnodar Scientific-Research Veterinary Institute, Krasnodar

\section{SUMMARY}

Data on assessment of lecithin preparation effect on liver toxicity experimentally induced in laboratory animals are presented. Experiments were carried out in rats kept under similar conditions that had been subjected to quarantine in animal facilities and demonstrated no apparent disease manifestations. The animals were divided into groups based on paired counterparts' principle. Acute toxic damage of liver was induced by single administration of carbon tetrachloride $(0.3 \mathrm{mg} / \mathrm{kg}$ of body weight). The rats demonstrated the following apparent signs of intoxication on day 2 after administration: anorexia, depression, dyspnea, fever. Per os administration of rape lecithin at a dose of $1 \mathrm{ml} / \mathrm{kg}$ of body weight one hour before hepatotoxicant administration and then daily for subsequent 30 days reduces intoxication manifestations and improves survivability of the rats. Pharmacological effect of lecithin includes biochemical characteristics improvement and functional state of liver of laboratory animals with experimentally induced acute hepatitis. Obtained data may provide grounds for application of lecithins as hepatoprotectors of natural origin in the form of biologically active supplements or active ingredients of pharmaceuticals intended for hepatic disease treatment in animals.

Key words: lecithin, phospholipids, hepatoprotectors, animals, toxic damages of liver experimentally induced hepatitis. 


\section{ВВЕДЕНИЕ}

Широкое распространение гепатопатий, сложность диагностики и вариативность терапевтических подходов вызывают у ветеринарных специалистов большой интерес к вопросам изучения данной проблемы. Многообразие функций печени как главной биохимической лаборатории организма определяет высокую вероятность возникновения ранних обменных нарушений различных органов и систем при гепатопатологии. В связи с этим при заболеваниях гепатобилиарной системы потребность в гепатопротективных средствах повышающих резистентность печени к действию химических агентов и нормализующих ее метаболизм в условиях напряжения детоксицирующей функции, в настоящее время остается высокой. При этом решающими факторами в пользу выбора препаратов подобной направленности являются безопасность хорошая переносимость и возможность длительного приема [6, 7].

На протяжении последних лет накоплен положительный опыт изучения и применения препаратов, в состав которых входят лецитины, при гепатитах, дистрофии, циррозе печени [1, 3]. Лецитины - общепринятое название группы жироподобных веществ, представляющих собой смесь фосфолипидов (65-75\%) с триглицеридами и незначительным количеством других составляющих. Лецитин является основным структурным компонентом всех клеточных мембран, поддерживающим постоянство внутренней среды клеток и участвующим во всех энергетических и обменных реакциях. Эмульгирующие свойства лецитина позволяют ему обеспечивать оптимальный химический состав желчи, препятствовать образованию холестериновых желчных камней, растворять уже возникшие твердые жировые отложения на стенках желчного пузыря и в желчных протоках [2, 3].

Одним из важнейших свойств лецитина является защита клеток от токсикантов, которая частично осуществляется за счет ингибирования процессов перекисного окисления липидов. Фосфолипиды, восстанавливая «упаковку» полиненасыщенных жирных кислот в мембране гепатоцитов, уменьшают доступ кислорода к ним, тем самым снижая скорость зарождения свободных радикалов. Лецитин укрепляет стенки клеточной мембраны гепатоцитов, способствует регенерации ткани печени, а также помогает ей справляться с детоксикацией организма от ядов и ксенобиотиков $[4,5]$.

Все эти свойства определяют широкий спектр биологического и фармакологического действия лецитина, что делает актуальным поиск перспективных подходов к фармакологической коррекции поражений печени за счет разработки препаратов на основе эссенциальных фосфолипидов.

Цель исследований - оценка эффективности лецитинового препарата при экспериментальном токсическом поражении печени лабораторных животных, вызванном тетрахлорметаном.

\section{МАТЕРИАЛЫ И МЕТОДЫ}

Эксперименты проведены на беспородных лабораторных крысах со средней массой тела 205,7 $\pm 3,1$ г. В опытах использовались животные, прошедшие карантинный режим вивария Краснодарского научно-исследовательского ветеринарного института и не имеющие внешних признаков заболеваний. Крысы содержались в одинаковых условиях на обычном пищевом режиме.

Для получения статистически достоверных результатов группы формировались по принципу парных аналогов. Исследования выполнены с соблюдением принципов, изложенных в Конвенции о защите позвоночных животных, используемых для экспериментов или в иных научных целях (г. Страсбург, Франция, 1986).

Изучение эффективности лецитинового препарата проводили на экспериментальной модели острого гепатита у крыс, вызванного тетрахлорметаном, в соответствии с «Методическими указаниями по изучению гепатозащитной активности фармакологических веществ» (Руководство по экспериментальному (доклиническому) изучению новых фармакологических веществ, под общей редакцией Р. У. Хабриева, 2005). Острое токсическое поражение печени моделировали однократным внутрибрюшинным введением четыреххлористого углерода $\left(\mathrm{CCl}_{4}\right)$ в дозе 0,3 мг/кг массы тела.

Лабораторные крысы были разделены на три группы по 10 животных: 1-я - опытная, 2-я - позитивный контроль и 3-я - интактный контроль. Животным 1-й группы за час до введения гепатотоксиканта и в последующие 30 дней ежедневно вводили лецитиновый препарат per os в дозе 1 мл/кг массы тела животного; 2-я группа после затравки находилась без лечения; 3-я группа состояла из здоровых животных, получавших растительное масло в эквиобъеме гепатопротектора по аналогичной схеме.

Эффективность гепатозащитного действия препарата оценивали по выживаемости лабораторных крыс, гравиметрическим показателям массы тела, клиническим признакам, а также степени изменения биохимических синдромов, наблюдающихся при поражениях печени: цитолиза - по активности в сыворотке аминотрансфераз (АсАТ, АлАТ); нарушения динамики желчи по уровню в сыворотке крови щелочной фосфатазы (ЩФ), содержанию билирубина и холестерина.

Образцы крови для биохимического анализа отбирали у 5 животных из каждой группы через 15 сут от начала опыта и через сутки после последнего введения лецитиновой композиции. Лабораторные исследования проводили на биохимическом анализаторе Vitalab Flexor с помощью наборов фирмы ELITech Clinical Systems.

Объект исследований - гепатопротекторный препарат на основе рапсового лецитина, состав которого представлен в таблице 1.

Статистическую обработку полученных результатов проводили с использованием пакетов специальных программ, исследование количественных признаков методом сравнения средних значений двух выборочных совокупностей с определением критерия Стьюдента и уровня значимости $(p)$.

\section{РЕЗУЛЬТАТЫ И ОБСУЖДЕНИЕ}

Проведенные исследования показали, что при введении крысам первых двух групп $\mathrm{CCl}_{4}$ у животных 2-й группы (без лечения) уже на второй день эксперимента появились внешние признаки интоксикации: отказ от корма, угнетенное состояние, одышка, повышение температуры тела. На третий день была зафиксирована 
Таблица 1

Содержание макро- и микронутриентов в рапсовом лецитине

\begin{tabular}{|c|c|}
\hline Показатель & Значение \\
\hline Фосфолипиды, г/100 г & 62,0 \\
\hline в том числе фосфатидилхолины & 16,0 \\
\hline фосфатидилэтаноламины & 15,5 \\
\hline фосфатидилсерины & 9,5 \\
\hline фосфатидные кислоты & 9,5 \\
\hline фосфатидилинозитолы & 10,0 \\
\hline дифосфатидилглицерины & 1,5 \\
\hline \multicolumn{2}{|l|}{ Полиненасыщенные жирные кислоты, г/100 г } \\
\hline линолевая $\mathrm{C}_{18: 2}$ (омега-6) & 15,2 \\
\hline линоленовая $C_{18: 3}$ (омега-3) & 3,1 \\
\hline Соотношение жирных кислот омега-6 : омега-3 & $5: 1$ \\
\hline Минеральные вещества, г/100 г & 6,81 \\
\hline Токоферолы (витамин Е), мг/100 г & 56,9 \\
\hline в том числе а-токоферол & 14,0 \\
\hline$\beta+\gamma$-токоферолы & 36,9 \\
\hline$\delta$-токоферол & 6,0 \\
\hline Фитостерины, мг/100 г & 650 \\
\hline в том числе $\beta$-ситостерол (провитамин D) & 445 \\
\hline
\end{tabular}

Макроэлементы, мг/100 г

\begin{tabular}{c|c}
\hline калий & 640 \\
\hline магний & 400 \\
\hline кальций & 710 \\
\hline фосфор & 2380 \\
\hline Микроэлементы, мг/100 г & \\
\hline железо & 5,3 \\
\hline медь & 0,2 \\
\hline
\end{tabular}

Таблица 2

Влияние лецитина на динамику массы тела лабораторных крыс при экспериментальном гепатите $(M \pm m)$

\begin{tabular}{|l|c|c|c|}
\multirow{2}{*}{\multicolumn{1}{c|}{ Группа }} & \multicolumn{3}{|c|}{ Масса тела (г) } \\
\cline { 2 - 4 } & Фон & Через 15 сут & Через 30 сут \\
\hline 1-я опытная $-\mathrm{CCl}_{4}+$ лецитин & $205,8 \pm 3,3$ & $206,8 \pm 2,4^{*}$ & $229,5 \pm 1,8^{* *}$ \\
\hline 2-я опытная - $\mathrm{CCl}_{4}$ & $206,5 \pm 2,4$ & $199,2 \pm 1,1$ & $203,7 \pm 2,9$ \\
\hline Контроль (интактные) & $204,7 \pm 3,5$ & $218,7 \pm 4,2$ & $231,0 \pm 2,5$ \\
\hline
\end{tabular}

Различия достоверны $\left({ }^{*} p \leq 0,05\right.$; ** $\left.p \leq 0,001\right)$ в сравнении с животными,

получавшими $\mathrm{CCl}_{4}$ без терапии. гибель одной крысы. При этом у крыс 1-й опытной группы, дополнительно получавших лецитин, клинические проявления интоксикации были менее выражены и регистрировались позже - к 4-м сут эксперимента при 100\%-й сохранности.

Гравиметрические исследования показали, что у крыс 2-й группы на протяжении всего эксперимента регистрировалась потеря массы тела, тогда как в группе с применением гепатопротектора к концу экспериментального периода вес животных хотя и не достиг показателей интактной группы, но фиксировался с положительной динамикой. При расчете процента прироста массы тела животных 1-й и 2-й групп разница составила $12,7 \%$ с высокой степенью достоверности $(p \leq 0,001)$ (табл. 2).

При биохимическом исследовании крови установлено, что при острой интоксикации четыреххлори стым углеродом происходит значительное изменение показателей метаболического состояния гепатоцитов (табл. 3).

Введение животным $\mathrm{CCl}_{4}$ вызвало выраженные изменения активности ферментов - маркеров функционального состояния печени. Во 2-й группе (без лечения) к середине опыта произошло достоверное увеличение активности АсАТ в 2,7 раза, а по завершении эксперимента разница с интактными животными составила 1,6 раза. Активность АлАТ увеличилась еще больше: на 15-е сут - в 3,7 раза и на 30-е сут - в 2 раза по сравнению с данными, полученными в контрольной группе крыс.

Активность АсАТ у животных 1-й группы, получавших лецитиновый препарат, к середине опыта была ниже значений этого же показателя во 2-й группе на $32,2 \%$ $(p \leq 0,01)$, а к концу - на $38,7 \%(p \leq 0,001)$, но при этом превысила значения, полученные в контрольной группе. В содержании АлАТ прослеживалась аналогичная динамика: разница на 15-е сут наблюдений составила $32,3 \%$ $(p \leq 0,001)$, а на $30-\mathrm{e}-37,7 \%(p \leq 0,01)$ относительно крыс 2-й группы, но значение показателя оставалось выше, чем у интактных животных.

По показателям желчеобразования у всех животных опытных групп была зарегистрирована гипербилирубинемия, причем концентрация общего билирубина в крови животных группы без лечения к концу эксперимента превысила показатели крыс 1-й группы в 1,9 раза. Уровень щелочной фосфатазы во 2-й группе к концу наблюдений вырос в 1,89 раза, а в 1-й только на 10,9\%. Подобная картина свидетельствует о наличии холестатического синдрома, вызванного нарушением желчевыделительной функции печени и поражением желчных канальцев (внутрипеченочный холестаз).

Введение $\mathrm{CCl}_{4}$ обусловило нарушение протеинсинтетической функции печени, что подтвердилось снижением содержания общего белка у животных 2-й группы на 13,2\% по отношению к здоровым крысам. Применение лецитиновых фосфолипидов позволило минимизировать развитие обменных нарушений. Разница между 1-й и 2-й группами составила 3,1\%.

Полученные результаты биохимических исследований сыворотки крови крыс позволяют констатировать, что при интоксикации животных $\mathrm{CCl}_{4}$ происходит повышение активности аминотрансфераз, свидетельствующее о повреждении мембран гепатоцитов, а также гибели клеток печени под действием гепатотоксиканта, 
Таблица 3

Влияние лецитина на биохимические показатели крови лабораторных крыс при экспериментальном гепатите $(M \pm m ; n=5)$

\begin{tabular}{|c|c|c|c|c|c|c|}
\hline \multirow{3}{*}{ Показатель } & \multicolumn{2}{|c|}{$\begin{array}{c}\text { 1-я опытная } \\
\mathrm{CCl}_{4}+\text { лецитин }\end{array}$} & \multicolumn{2}{|c|}{$\begin{array}{l}\text { 2-я опытная } \\
\mathrm{CCl}_{4}\end{array}$} & \multicolumn{2}{|c|}{$\begin{array}{c}\text { Контроль } \\
\text { (интактные) }\end{array}$} \\
\hline & \multicolumn{6}{|c|}{ Сутки после интоксикации } \\
\hline & 15 & 30 & 15 & 30 & 15 & 30 \\
\hline Общий белок, г/л & $88,5 \pm 3,25^{*}$ & $81,4 \pm 2,28^{* *}$ & $93,3 \pm 3,06$ & $74,1 \pm 3,83$ & $82,4 \pm 1,92$ & $83,9 \pm 2,11$ \\
\hline Мочевина, мМ/л & $6,83 \pm 0,27$ & $7,12 \pm 0,17^{*}$ & $6,64 \pm 0,32$ & $3,82 \pm 0,41$ & $7,25 \pm 0,55$ & $7,38 \pm 0,37$ \\
\hline АсАТ, ЕД/л & $194,9 \pm 7,6^{* *}$ & $125,7 \pm 6,1^{* * *}$ & $257,6 \pm 5,8$ & $174,3 \pm 7,6$ & $95,5 \pm 3,5$ & $106,4 \pm 5,0$ \\
\hline АлАТ, ЕД/л & $158,4 \pm 4,2^{* * *}$ & $90,8 \pm 3,9 * *$ & $209,6 \pm 8,9$ & $125,0 \pm 6,2$ & $57,3 \pm 4,8$ & $63,5 \pm 3,9$ \\
\hline ЩФ, ЕД/л & $703,9 \pm 17,0^{*}$ & $648,5 \pm 9,7^{*}$ & $711,0 \pm 16,4$ & $1107,2 \pm 25,3$ & $576,5 \pm 13,5$ & $585,0 \pm 17,0$ \\
\hline Холестерин, мМ/л & $2,13 \pm 0,22^{* *}$ & $1,25 \pm 0,13^{* *}$ & $7,83 \pm 0,09$ & $5,45 \pm 0,18$ & $1,53 \pm 0,03$ & $1,48 \pm 0,02$ \\
\hline $\begin{array}{l}\text { Общий билирубин, } \\
\text { мкМ/л }\end{array}$ & $20,7 \pm 3,5^{* * *}$ & $16,3 \pm 2,7^{* * *}$ & $43,7 \pm 4,3$ & $30,9 \pm 2,9$ & $9,4 \pm 1,2$ & $10,5 \pm 0,9$ \\
\hline
\end{tabular}

Различия достоверны $\left({ }^{*} p \leq 0,05 ; * * 0,01 ; * * * 0,001\right)$ в сравнении с животными, получавшими $\mathrm{CCl}_{4}$ без терапии.

что приводит к выходу внутриклеточных субстанций в кровь и лимфу. Данный процесс сопровождается внутрипеченочным холестазом и нарушением протеинсинтетической функции печени. Применение лецитиновых фосфолипидов улучшает параметры биохимических констант гомеостаза и функционального состояния печени подопытных крыс на фоне токсического поражения.

\section{ЗАКЛЮЧЕНИЕ}

Таким образом, резюмируя результаты изучения эффективности лецитина при экспериментальном поражении печени лабораторных животных, можно утверждать, что он обладает выраженными гепатопротективными свойствами, способствующими снижению общего токсического, цитолитического и холестатического проявлений повреждающего действия токсиканта.

Полученные данные могут послужить основанием для применения рапсовых лецитинов в качестве перспективных гепатопротекторов природного происхождения с возможностью их использования как биологически активных добавок или действующих начал лекарственных средств, предназначенных для лечения заболеваний печени у животных.

\section{СПИСОК ЛИТЕРАТУРЫ}

1. Ипатова О. М. Фосфоглив: механизм действия и применение в клинике: дис. ... д-ра биол. наук // М.: Изд-во ГУ НИИ биомед. химии РАМН, 2005. - 319 с.

2. Корнен Н. Н., Викторова Е. П., Евдокимова О. В. Методологические подходы к созданию продуктов здорового питания // Вопросы питания. - 2015. - Т. 84, № 1. - С. 95-99.

3. Кунц Э., Гундерманн К.-Й, Шнайдер Э. «Эссенциальные» фосфолипиды в гепатологии (экспериментальный и клинический опыт) // Терапевтический архив. - 1994. - № 2. - С. 660-672.

4. Никитин И. Г. Гепатопротекторы: мифы и реальные возможности // Фарматека. - 2007. - № 13. - С. 14-18.

5. Огай М. А., Степанова Э. Ф., Малявина В. В. Использование лецитина в мягких лекарственных формах // Научные ведомости БелГУ. Серия: Медицина. Фармация. - 2011. № 22 (117), вып. 16/2. - С. 159-163.

6. Семененко М. П., Кузьминова Е. В., Фомин О. А. Новые подходы к лабораторной диагностике болезней печени у высокопродуктивного молочного скота // Ветеринария Кубани. 2014. - № 3. - C. 11-13.

7. Molecules of medium mass as an integral indicator of endogenous intoxication in the diagnosis of hepatopathy and its effect on improving the economic efficiency of veterinary measures in the field of dairy farming / M. P. Semenenko, E. V. Kuzminova, E. V. Tyapkina [et al.] // J. Pharm. Sci. \& Res. - 2017. - Vol. 9, No. 9. P. 1573-1575. 